\title{
On Hypsometric Curve and Morphological Analysis of The Collapsed Irrigation Reservoirs
}

\section{Donghyun Kim}

Inha University https://orcid.org/0000-0002-9785-8657

\section{Jongsung Kim}

Inha University

\author{
Wonjoon Wang \\ Inha University \\ Haneul Lee \\ Inha University \\ Myungjin Lee \\ Inha University \\ Hung Soo Kim ( $\square$ sookim@inha.ac.kr) \\ Inha University
}

\section{Research Letter}

Keywords: hypsometric curve, cluster analysis, volume(V)-area(A)-depth(H), morphology index

Posted Date: October 18th, 2021

DOl: https://doi.org/10.21203/rs.3.rs-948338/v1

License: (c) (i) This work is licensed under a Creative Commons Attribution 4.0 International License. Read Full License

Version of Record: A version of this preprint was published at Water on March 14th, 2022. See the published version at https://doi.org/10.3390/w14060907. 


\section{On hypsometric curve and morphological analysis of the collapsed}

2

3

4

5

6

$7 \quad{ }^{1}$ Department of Civil Engineering, Inha University, Incheon 22212, Korea

8

9

10

11

12

13

14

15

16

17

18

\section{irrigation reservoirs}

Donghyun Kim ${ }^{1}$, Jongsung Kim², Wonjoon Wang ${ }^{1}$, Haneul Lee ${ }^{1}$, Myungjin Lee ${ }^{2}$, Hung Soo

$\mathrm{Kim}^{1 *}$

${ }^{2}$ Institute of Water Resources System, Inha University, Incheon 22212, Korea 


\section{Abstract}

20 To identify the drought and flood control functions of an irrigation reservoir, research on 21 hydrological analysis and its impact needs to be conducted. To this end, geographical 22 characteristics, such as the cross section of the reservoir, are important, but such information is 23 insufficient. Therefore, this study aimed to identify the topographic and morphological 24 characteristics of reservoirs without measured data using their geographical information. In 25 addition, an attempt was made to identify the morphological characteristics of reservoirs that had collapsed due to aging and the increased frequency of occurrence of strong rainfall intensity 27 caused by climate change. Ten reservoirs, including the Ga-Gog Reservoir located in Miryang city, Gyeongsangnam province, South Korea with measured data, were selected as target reservoirs. The topographic information of the target reservoirs was constructed using topographical maps and GIS techniques. Based on the information, the volume (V)-area (A)-depth (H) relationship and the hypsometric curve $(\mathrm{HC})$ according to the relative height $(\mathrm{h} / \mathrm{H})$ and relative area (a/A) were created. When the volume of each reservoir estimated using topographic information was compared with the measured volume, the error rate was found be between 0.23 and $14.27 \%$. In addition, two reservoirs that had collapsed near Miryang city were added, and the V-A-H relationship and HCs were created based on the topographic information. In addition, the morphology index, storage-area of full water-levee height relationship, and storage-area of full water relationship were analyzed to identify the morphological characteristics of the reservoirs. The analysis results showed that the collapsed reservoirs had a relatively high water depth and a large area. In addition, similar types of reservoirs were grouped by conducting cluster analysis using basic specifications, such as the reservoir watershed, storage, and area of full water. When the cluster analysis results were analyzed based on $\mathrm{HC}$, the reservoirs were grouped into three shapes: convex upward shape (youthful stage), relatively flat shape (mature stage), and convex 
43 downward shape (old stage). The HCs of the collapsed reservoirs exhibited the convex downward 44 shape (old stage), indicating that they were subjected to considerable erosion due to aging. In 45 other words, considerable erosion makes the allowable storage capacity insufficient due to the 46 large amount of sediment accumulated in reservoirs and reduces their flood control capacity, 47 which may cause them to collapse during heavy rainfall. Therefore, it is expected that identifying 48 the potential causes of reservoir collapse through the morphological characteristics and HCs of 49 reservoirs will support the operation and management of reservoirs for reducing flood damage. 50

51 Keywords: hypsometric curve, cluster analysis, volume(V)-area(A)-depth(H), morphology index 52 


\section{Introduction}

54 The precipitation by heavy rainfall, monsoon rains, and typhoons, which occur during the summer rainy season, is stored and used in the next year. To this end, water is secured and water resources are managed through hydraulic facilities, such as dam reservoirs for various types of water and irrigation reservoirs for agriculture. Owing to the increasing variability of precipitation under the influence of climate change and an imbalance in precipitation by region, however,

59 reservoirs are becoming more vulnerable to droughts and floods depending on the region. In particular, the flood damage caused by the collapse of irrigation reservoirs has occurred because high rainfall intensity and heavy rainfall have occurred more frequently (Kim et al, 2019). According to the National Disaster Management Research Institute, there are 16,791 reservoirs in South Korea, including 3,406 reservoirs managed by the Korea Rural Community Corporation and 13,385 reservoirs managed by local governments, and their specifications vary depending on the topographic characteristics at the time of their completion (National Disaster Management Research Institute, 2019).

To respond to drought and flood control functions, among the several functions of reservoirs, it is necessary to conduct research on hydraulic and hydrological analysis and its impact. For accurate research, basic research on the topographic and morphological characteristics of reservoirs is important. While the reservoir storage rate has been monitored and systematic management has been performed for the reservoirs managed by the Korea Rural Community

72 Corporation, significantly insufficient management has been performed for the small irrigation reservoirs managed by local governments (Kim et al, 2020). Many of the existing irrigation

74 reservoirs in Korea are aged more than 50 years (Hong et al., 2004; Kim et al., 2019), and they 75 are small reservoirs with an irrigation scale of 100 ha $\left(0.01 \mathrm{~km}^{2}\right)$ or less. In addition, reservoirs have been inefficiently managed because management personnel are limited and considerable cost 
77 is required (You et al., 2007). Since reservoirs located throughout the country have different 78 shapes and characteristics, they also exhibit different damage patterns during heavy rainfall. Since 79 the flood damage patterns of irrigation reservoirs by heavy rainfall are correlated with the 80 topographic and physical factors of the reservoirs, it is necessary to analyze the topographic 81 characteristics of the reservoirs and identify their morphological or physical characteristics (Graf, 1999; McDonald et al., 2012; Kim et al., 2020).

In recent years, precision measuring instruments have been used for efficient management of reservoirs through accurate specifications, such as the area by water level and the storage capacity. According to previous studies, reservoirs are measured using manned and unmanned boats equipped with GPS and water depth sensors to measure the topography, area by water level, and storage capacity in reservoirs (Chang et al., 2003; Park and Jeong., 2005; Choi and Lee., 2007; Guerrero and Lamberti., 2011; Song et al., 2018; Ilci et al., 2019). Considerable time and cost, however, are required inefficiently to measure accurate specifications, such as the area by water

90 level and storage capacity, for all reservoirs. In addition, as reservoirs are located in mountainous areas, it is difficult for water depth measuring instruments to access them. Therefore, in this study, the depth of water and the area were obtained using topographical maps and GIS techniques. To quantitatively analyze the topographic and morphological characteristics of reservoirs using these data, an attempt was made to apply the hypsometric curve (HC), which is used for river basins, to reservoirs.

Langbein et al. (1947) utilized HC to identify the topographic characteristics of the basins in

97 the northeastern United States. In addition, HCs were created by identifying the area by water level and the storage capacity using the topographic information of river basins, reservoirs, and wetlands, and the topographic and morphological characteristics of basins were identified and utilized as basic data (Hayashi et al, 2000; Park et al., 2000; Oertel et al., 2000; Kim et al., 2002; 
101 Kang et al., 2005; Nam et al., 2015). For reservoirs, the morphology index and HC are important

102 information for research on topographic characteristics, and studies that can quantitatively present

103 topographic characteristics are also required (Takeuchi , 1997; Leonard et al., 1999; Lehner et al.,

104 2004; Dargahi \& Setegn., 2011; Li et al., 2014; Zhang et al., 2017; Lopes et al., 2018; Munar et

105 al., 2018; Andrade et al., 2020).

106 If the topographic and morphological characteristics of reservoirs with the reliability of

107 quantitative data can be identified using topographical maps and GIS techniques, it will be

108 possible to indirectly secure topographic information on reservoirs located in mountainous or

109 remote areas with poor accessibility. In addition, the secured topographic information can be

110 utilized for the hydraulic and hydrological analysis and management of reservoirs.

111 Therefore, the purpose of this study is to construct the geometry of reservoirs using their

112 topographic information and to evaluate its accuracy through a comparison with the measured

113 data and volumes of the reservoirs. In addition, HCs were created for reservoirs to understand the

114 geometry of the reservoirs and to identify the area by elevation and storage capacity. In addition,

115 an attempt was made to quantitatively present the morphology index through relational analysis

116 that used the basic specifications of reservoirs, such as the storage capacity and area of full water,

117 and to group similar types of reservoirs through cluster analysis. Based on this, the topographic

118 and morphological analysis of reservoirs that had collapsed due to flooding was conducted to

119 identify the potential causes of collapse.

120

2.1 The area-volume relationship for reservoirs according to the depth of water

\section{Research Method}

124 geometry of the reservoir is very important. Reservoirs, however, have different geometry, and it 
125 is not possible to accurately express the geometry of a reservoir with a cross section. In this study,

126 it was assumed that the A-h and V-h relationships can be expressed with inverse functions. In

127 addition, a basic mathematical theory was developed based on previous studies to induce first-

128 order equations for these relationships. Here, it can be inferred that the A-h and V-h relationships are interdependent. Thus, based on this, the equations were induced (Hayashi et al, 2000; Kim et al, 2002).

131

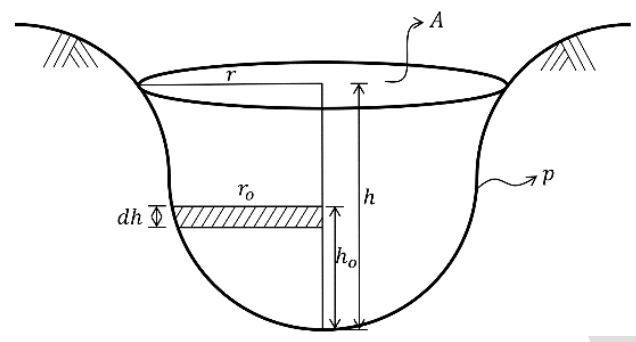

Figure. 1 The structure of reservoir

The volume of the reservoir can be obtained by integrating the area along the water depth as shown in Eq. (1).

$\mathrm{V}=\int_{0}^{h} A(\eta) d \eta$

139

where $\eta$ is an arbitrary variable for water depth, $V$ is the volume of the reservoir, $h$ is the water

141 depth from the lowest point of the reservoir to the water surface, $h_{0}$ is the water depth to the

142 infinitesimal area of the reservoir, and A is the surface area of the wetland.

144 A is assumed to be flat and can be obtained considering the wetland slope between dh, which can 145 be expressed as Eq. (2). 
$147 \quad \frac{y}{y_{o}}=\left(\frac{r}{r_{0}}\right)^{p}$

149 where $\mathrm{y}$ is the altitude of the ground surface corresponding to $\mathrm{h}, y_{0}$ is the unit altitude of the

150 ground surface, $\mathrm{r}$ is the radius of the wetland, $r_{0}$ is the radius of an arbitrary infinitesimal area of

151 the wetland, and $\mathrm{p}$ is the shape factor for the side slope of the wetland.

152

153 Since the area is $\mathrm{A}=\pi r^{2}$ if it is obtained using a conventional method without considering the

154 slope of the reservoir, the change in area depending on the water depth is $\pi r_{0}^{2} \propto h_{0}$ and $\pi r^{2} \propto$

$155 h_{0}$. Therefore, Eq. (3) can be expressed from $h_{0} \pi r^{2}=h \pi r_{0}^{2}$.

156

$157 \quad \frac{r^{2}}{r_{0}^{2}}=\frac{h}{h_{0}}$

158

159 In addition, from Eq. (2) and (3), the relationship of $\frac{y}{y_{0}}=\left(\frac{r}{r_{0}}\right)^{p} \rightarrow\left(\frac{h}{h_{0}}\right)^{\frac{2}{p}}$ and Eq. (4) can be 160 inferred.

161

$162 \quad \mathrm{r}^{2} \sim\left(\frac{r}{r_{0}}\right)^{p} \pi r_{0}^{2}$

163

164 The area can be expressed using Eq. (4) as shown in Eq. (5).

165

166

$$
\mathrm{A}=\pi r^{2}=\pi r_{0}^{2}\left(\frac{h}{h_{0}}\right)^{\frac{2}{p}}
$$

168 Therefore, the change in area depending on the slope can be expressed as Eq. (6). 
$\mathrm{A}=\pi r_{0}^{2}\left(\frac{h}{h_{0}}\right)^{\frac{2}{p}}=\mathrm{S}\left(\frac{h}{h_{0}}\right)^{\frac{2}{p}}$

171

172 The volume that applied the shape factor of the sloped cross section of the reservoir can be 173 expressed as Eq. (7).

174

$175 \mathrm{~V}=\int_{0}^{h} A(\eta) d \eta$

176

$177 \mathrm{~A}(\eta)$ can be introduced from Eq. (6), and Eq. (6) can be expressed as Eq. (8).

178

$179 \quad \mathrm{~V}=\frac{S}{(1+2 / p)} \frac{h^{1+\left(\frac{2}{p}\right)}}{h_{0}^{2 / p}}$

\subsubsection{Morphology index}

The morphology index of a reservoir is quantified using the average depth and area of full water of the reservoir. According to Leonard and Crouzet (1999), a morphology index of 10.5 or higher belongs to a deep lake and a morphology index of 0.6 to 10.4 represents a normal lake. A morphology index of 0.5 or less is classified as a shallow lake. Eq. (9) shows the morphology index applied to reservoirs.

\subsubsection{Storage-area of full water-levee height relationship}

Lehner et al. (2004) estimated the storage-area of full water-levee height relationship for reservoirs and lakes in the world as shown in Eq. (10), and showed that the storage is approximately $29 \%(=1 / 3.42)$ of the product of the area of full water and the levee height. 


\subsubsection{Storage-area of full water relationship}

Takeuchi (1997) estimated the storage-area of full water relationship for reservoirs in the world with an area of full water of $36.1 \mathrm{~km}^{2}$ or high and a storage of $0.5 \mathrm{~km}^{3} \rrbracket$ or higher as shown in Eq. (11).

$$
\text { storage }\left(10^{6} \times \mathrm{m}^{3}\right)=9.208 \times \text { areaof full water }{ }^{1.114}\left(\mathrm{~km}^{2}\right)
$$

\subsection{Cluster analysis}

Cluster analysis is a method of classifying data with similar characteristics into groups based on the characteristics possessed by multiple subjects. It is divided into hierarchical cluster analysis and non-hierarchical cluster analysis (Kyoung et al., 2007; Han et al., 2014; Nam et al., 2015). Representative methods for hierarchical cluster analysis include clustering methods that use the distance between data, such as shortest connection and longest connection. A representative method for non-hierarchical cluster analysis is K-means clustering. K-means cluster analysis classifies data with similar characteristics into $\mathrm{K}$ groups. It is a method of grouping data in the close distance from a centerpoint, which is the average of the data in each cluster. In this study, K-means cluster analysis was conducted to determine optimal clusters by minimizing the distance between data in each cluster based on the centerpoint, and the cluster analysis process was terminated at the stage where the arbitrarily defined centerpoint of each cluster could no longer minimize the error. Figure. 2 shows the concept of cluster analysis among unsupervised methods.

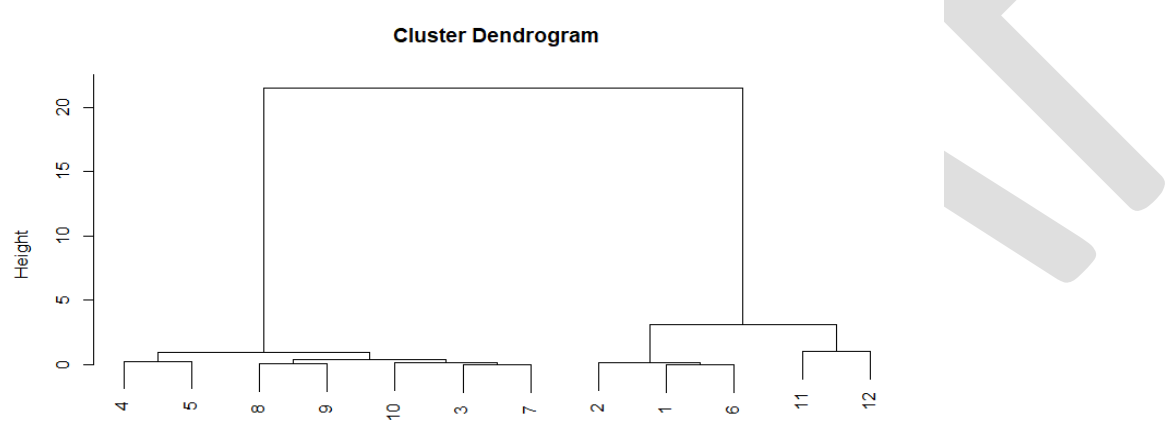

$$
\text { hclust (*, "ward.D") }
$$

Figure. 2 Concept of cluster analysis

\section{Target Basin Selection and HC Calculation}

\subsection{Target basin selection}

Ten reservoirs, including the Ga-Gog Reservoir located in Miryang city, Gyeongsangnam province, were selected as target reservoirs in this study. They were measured using unmanned water depth measuring equipment by the National Disaster Management Research Institute. The total storage capacity is the height from the reservoir bottom to the full water level. Since the dead storage level could not be identified, the total storage was compared and analyzed. In this study, the reservoir data measured by the National Disaster Management Research Institute were used. The locations of the ten reservoirs, including the Ga-Gog Reservoir, are shown in Figure. 3. The names of the ten reservoirs are R(1): Ga-Gog, R(2): Nae-Gog, R(3): Dae-Gog, R(4): Sam-Son, R(5): Deog-Am, R(6): Un-Jeong, R(7): Yong-Po, R(8): O-Cho, R(9): Ga-Gog2, and $\mathrm{R}(10): \mathrm{U}-\mathrm{Gog} 2$ (Table 1). 


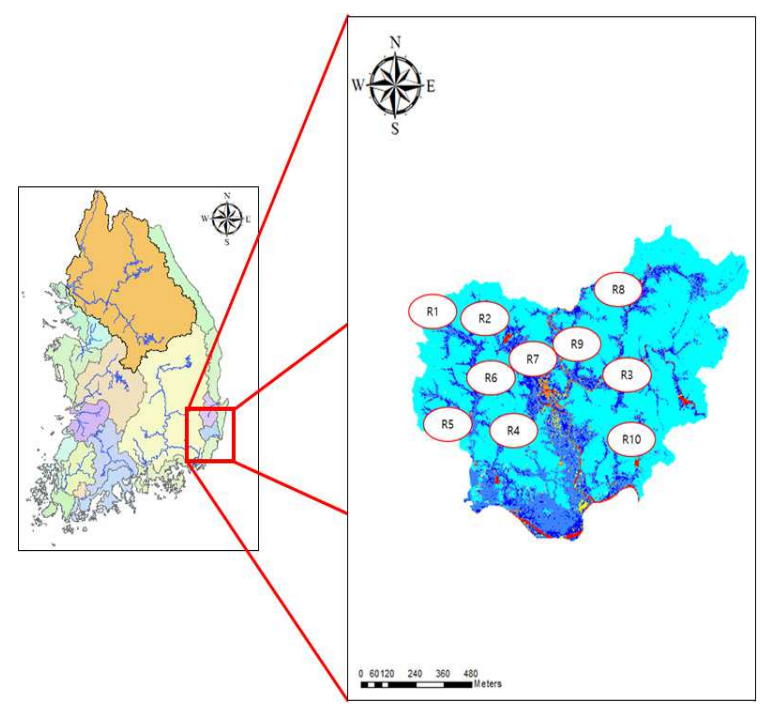

230 Figure. 3 Study area

231 Table 1. Reservoir name

Table 1. Reservoir name
\begin{tabular}{|c|c|}
\hline Classification & Name \\
\hline \hline R1 & Ga-Gog \\
\hline R2 & Nae-Gog \\
\hline R3 & Dae-Gog \\
\hline R4 & Sam-Son \\
\hline R5 & Deog-Am \\
\hline R6 & Un-Jeong \\
\hline R7 & Yong-Po \\
\hline R8 & O-Cho \\
\hline R9 & Ga-Gog2 \\
\hline R10 & U-Gog2 \\
\hline
\end{tabular}

\subsection{Creation of digital elevation models (DEMs) for the target reservoirs}

The target reservoirs were modeled based on the digital topographic maps (1:25,000) of Miryang city, Gyeongsangnam province provided by the National Spatial Information Portal. To quantitatively identify the altitude and topographic characteristics of the reservoirs, the procedure of (1) to (6) in Figure. 4 was performed. In other words, (1) the contour line layer is extracted. (2) Watershed boundaries are added. (3) A digital topographic map is built for each reservoir watershed. (4) TIN data are generated for each reservoir watershed. (5) Numerical data are extracted. (6) Cell interval 5m X 5m DEM is created for each reservoir watershed. For the ten reservoirs, including the Ga-Gog Reservoir, topographic information was constructed using topographical maps and GIS techniques, and the location and the area by water depth were modeled for each reservoir as shown in Figure. 5. 


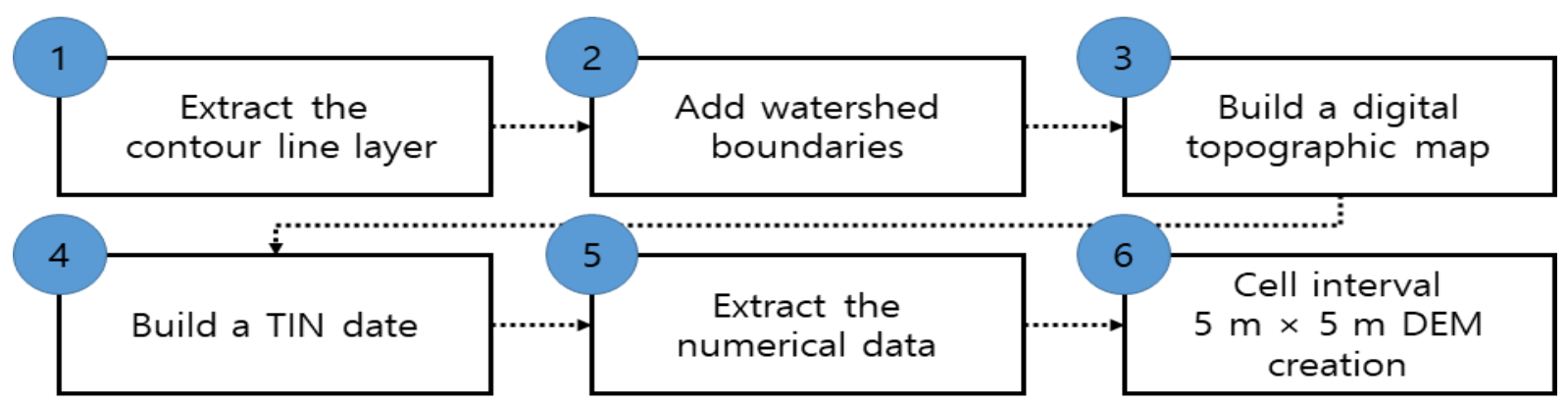

Figure. 4 Reservoir modeling flow chart

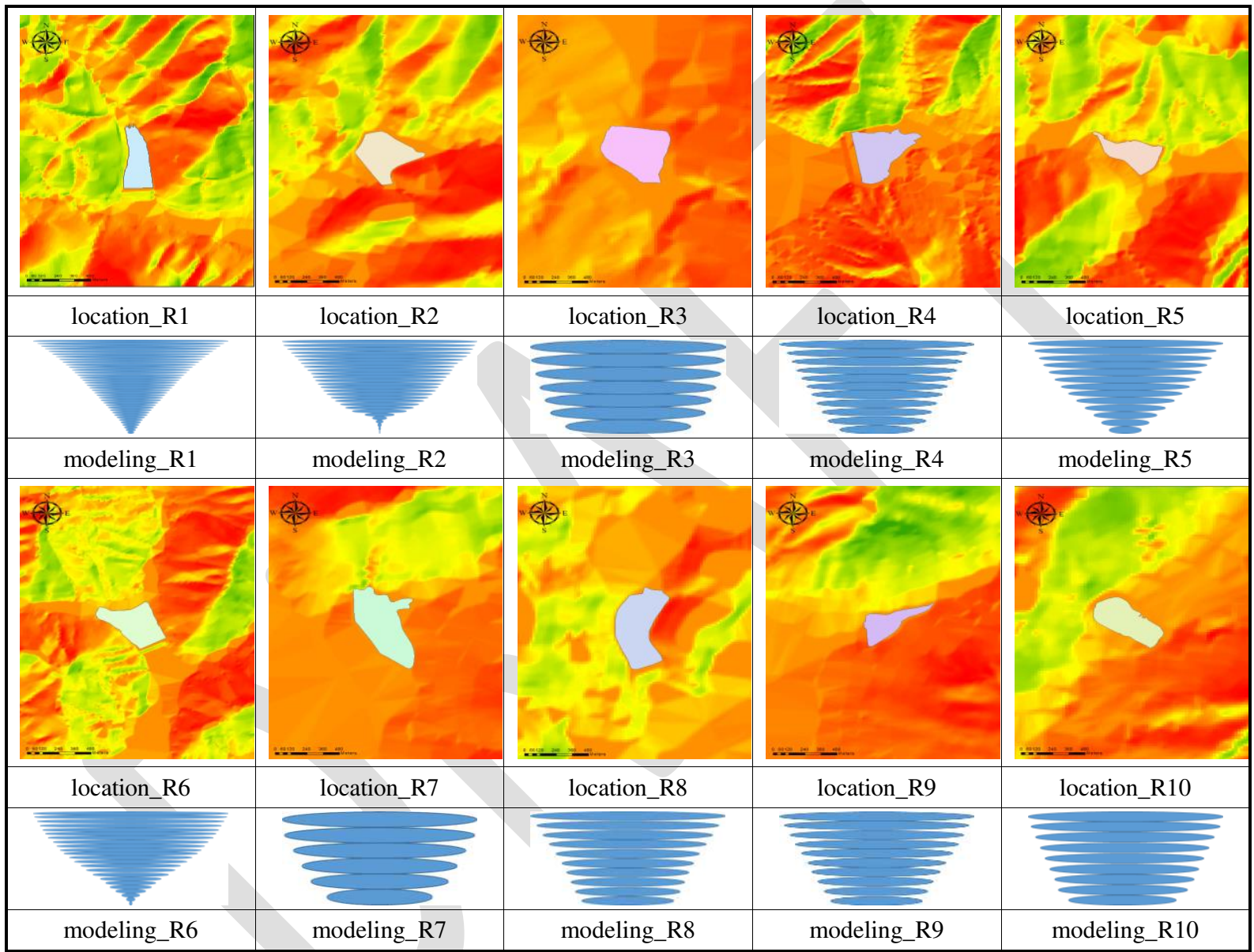

Figure. 5 Study reservoir location and modeling

\section{Characteristics Analysis according to the HCs of the Reservoirs}

\subsection{HC calculation}

Figure. 6 shows HCs for river basins. In this study, an attempt was made to apply HC to reservoirs. HC can be mainly divided into the youthful stage, mature stage, and old stage. The youthful stage has the characteristics of a basin where the original ground surface is not significantly eroded. The mature stage has the characteristics of a basin where the ground surface is significantly eroded. The old stage has characteristics close to those of a peneplain because the ground surface is further eroded. In other words, for reservoirs, the old stage exhibits the highest level of erosion, followed by the mature stage 
and youthful stage (Sarp et al., 2011). Erosion causes the allowable storage capacity to be insufficient due to the accumulated sediment in reservoirs, which reduces the flood control capacity of reservoirs and may lead to their collapse during heavy rainfall.

\subsection{Analysis of the morphological characteristics of the reservoirs}

Based on the topographic information constructed using topographical maps and GIS techniques, HC according to the relative height $(\mathrm{h} / \mathrm{H})$ and relative area $(\mathrm{a} / \mathrm{A})$ was created for each reservoir. The $\mathrm{HC}$ of a reservoir is created by calculating the area by elevation and then connecting the altitude of the reservoir above sea level to the cumulative area above a certain altitude. In this instance, the Y-axis was defined as the ratio of a certain height (h) to the total height of the reservoir watershed (H) and $\mathrm{X}$-axis as the ratio of the cumulative area (a) above a certain height (h) to the total area of the reservoir watershed (A). In other words, the relative height was set to $\mathrm{h} / \mathrm{H}$ and the relative area to $\mathrm{a} / \mathrm{A}$. Since $\mathrm{h} / \mathrm{H}$ and a/A are relative values for each reservoir watershed, the volume and area were calculated for each reservoir while $\mathrm{h}$ was increased from zero by $0.5 \mathrm{~m}$.

Tables 2, 3, 4, and 5 show the area and volume according to the change in $\mathrm{h}$ for each reservoir. For the reservoirs, the A$\mathrm{h}$ relationship curves are shown in Figure. 7 and the V-h relationship curves in Figure. 8. In addition, HC was created for each reservoir using the $\mathrm{a} / \mathrm{A}$ and $\mathrm{h} / \mathrm{H}$ ratios (Figure. 9). A comparison with the volumes of the reservoirs measured using unmanned water depth measuring equipment by the National Disaster Management Research Institute revealed that the error rate ranged from 0.23 to $14.27 \%$ and the average error rate was $5.03 \%$ (Table 6).

To identify the characteristics of the reservoirs, the morphology index and the storage-area of full water-levee height relationship used by Leonard and Crouzet (1999) and Lehner et al. (2004) were utilized. Leonard and Crouzet (1999) quantified the morphology index for a reservoir using the average depth and area of full water of the reservoir. In this study, the average morphology index of the ten reservoirs, including the Ga-Gog Reservoir, was found to be approximately 4.36, and thus they were classified as normal lakes. The R3, R4, R5, R7, R8, R9, and R10 reservoirs exhibited low morphology index values, indicating that they had lower depths compared to other reservoirs. The morphology index results also showed that the R1, R2, and R6 reservoirs had high depths.

Lehner et al. (2004) estimated the relationship for reservoirs and lakes in the word. In this study, the storage-area of full waterlevee height relationship was analyzed for the target reservoirs and the relationship between the storage and the product of the area of full water and the levee height was derived as shown in Eq. (12).

$$
\text { area of full water }\left(m^{2}\right)=3.98 \times \frac{\text { storage }\left(m^{3}\right)}{\text { levee height }(m)}
$$

The analysis results showed that the R3, R4, R5, R7, R8, R9, and R10 reservoirs had a relatively smaller area of full water compared to the R1, R2, and R6 reservoirs.

Takeuchi (1997) estimated the relationship between the area of full water and the storage for reservoirs in the world with an area of full water of $36.1 \mathrm{~km}^{\wedge} \llbracket 2$ 2》 or higher and a storage of $\left.0.5 \mathrm{~km}^{\wedge} \llbracket 3\right]$ or higher. In this study, the relationship was analyzed for reservoirs in Korea and Eq. (13) was derived.

$$
\text { storage }\left(10^{6} \times \mathrm{m}^{3}\right)=2.63 \times \text { areaof full water }{ }^{1.114}\left(\mathrm{~km}^{2}\right)
$$

The results of the storage-area of full water relationship showed that the R3, R4, R5, R7, R8, R9, and R10 reservoirs had a relatively smaller storage compared to the R1, R2, and R6 reservoirs (Table. 7). 
Table 2. Area according to the change in reservoir height, Measurement

\begin{tabular}{|c|c|c|c|c|c|c|c|c|c|c|}
\hline \multirow{2}{*}{$\mathbf{h}(\mathbf{m})$} & R1 & $\mathbf{R 2}$ & R3 & R4 & R5 & R6 & R7 & R8 & R9 & R10 \\
\hline & \multicolumn{10}{|c|}{$\mathbf{A}\left(m^{2}\right)$} \\
\hline 0 & 0 & 0 & 0 & 0 & 0 & 0 & 0 & 0 & 0 & 0 \\
\hline 0.5 & 1,012 & 59 & 4,033 & 1,488 & 107 & 7 & 18 & 1,073 & 53 & 4,299 \\
\hline 1 & 1,542 & 227 & 5,000 & 4,177 & 2,554 & 151 & 3,385 & 1,704 & 1,467 & 6,950 \\
\hline 1.5 & 2,088 & 433 & 5,350 & 5,510 & 3,767 & 1,060 & 11,230 & 2,330 & 2,071 & 8,360 \\
\hline 2 & 2,634 & 809 & 5,670 & 6,180 & 5,020 & 3,053 & 14,660 & 2,984 & 2,628 & 9,020 \\
\hline 2.5 & 3,164 & 1,646 & 5,960 & 6,760 & 6,390 & 6,310 & 16,560 & 3,679 & 3,151 & 9,640 \\
\hline 3 & 3,694 & 3,402 & 6,220 & 7,360 & 7,770 & 10,370 & 18,380 & 4,332 & 3,752 & 10,270 \\
\hline 3.5 & 4,477 & 6,260 & 6,300 & 7,920 & 9,030 & 14,330 & 20,290 & 5,880 & 4,354 & 10,910 \\
\hline 4 & 5,260 & 7,870 & & 8,480 & 10,200 & 17,230 & 20,760 & 6,690 & 4,910 & 11,550 \\
\hline 4.5 & 5,905 & 9,080 & & 9,030 & 11,190 & 20,840 & & 7,270 & 5,480 & 12,210 \\
\hline 5 & 6,550 & 10,230 & & 9,580 & 12,130 & 25,910 & & 7,830 & 6,010 & 12,590 \\
\hline 5.5 & 7,235 & 11,250 & & 10,150 & 12,990 & 30,470 & & 8,440 & 6,560 & \\
\hline 6 & 7,920 & 12,180 & & 10,970 & 13,690 & 34,170 & 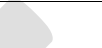 & 9,170 & 7,180 & \\
\hline 6.5 & 8,720 & 12,950 & & & 14,410 & 38,610 & & 10,050 & 7,730 & \\
\hline 7 & 9,520 & 13,600 & & & 15,470 & 42,050 & & 10,880 & 8,240 & \\
\hline 7.5 & 10,190 & 14,210 & & & & 45,860 & & 11,650 & 8,760 & \\
\hline 8 & 10,860 & 14,810 & & & & 48,400 & & 12,460 & 9,230 & \\
\hline 8.5 & 11,620 & 15,410 & & & & 50,700 & & & & \\
\hline 9 & 12,380 & 16,040 & & & & 53,100 & 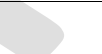 & & & \\
\hline 9.5 & 13,190 & 16,670 & & & & 56,600 & & & & \\
\hline 10 & 14,000 & 17,340 & & & & 58,500 & & & & \\
\hline 10.5 & 14,705 & 18,110 & & & & 60,300 & & & & \\
\hline 11 & 15,410 & 19,030 & & & 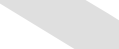 & 62,100 & & & & \\
\hline 11.5 & 16,195 & 19,890 & & & & 64,000 & & & & \\
\hline 12 & 16,980 & 20,700 & & & & 65,900 & & & & \\
\hline 12.5 & 17,860 & 21,420 & & & & 66,800 & & & & \\
\hline 13 & 18,740 & 22,090 & & & & & & & & \\
\hline 13.5 & 19,720 & 22,530 & & & & & & & & \\
\hline 14 & 20,700 & & & & & & & & & \\
\hline 14.5 & 21,715 & & & & & & & & & \\
\hline 15 & 22,730 & & & & & & & & & \\
\hline 15.5 & 23,845 & & & & & & & & & \\
\hline 16 & 24,960 & & & & & & & & & \\
\hline 16.5 & 26,135 & & & & & & & & & \\
\hline 17 & 27,310 & & & & & & & & & \\
\hline 17.5 & 28,510 & & & & & & & & & \\
\hline 18 & 29,710 & & & & & & & & & \\
\hline 18.5 & 31,070 & & & & & & & & & \\
\hline
\end{tabular}


302 Table 3. Area according to the change in reservoir height, Estimation

\begin{tabular}{|c|c|c|c|c|c|c|c|c|c|c|}
\hline \multirow{2}{*}{$\mathbf{h}(\mathbf{m})$} & R1 & $\mathbf{R 2}$ & R3 & R4 & R5 & R6 & R7 & R8 & R9 & R10 \\
\hline & \multicolumn{10}{|c|}{$\mathbf{A}\left(m^{2}\right)$} \\
\hline 0 & 0 & 0 & 0 & 0 & 0 & 0 & 0 & 0 & 0 & 0 \\
\hline 0.5 & 1,012 & 59 & 4,029 & 1,484 & 107 & 7 & 18 & 1,030 & 53 & 4,084 \\
\hline 1 & 1,542 & 227 & 4,995 & 4,164 & 2,549 & 151 & 3,375 & 1,635 & 1,466 & 6,603 \\
\hline 1.5 & 2,088 & 432 & 5,345 & 5,493 & 3,759 & 1,059 & 11,196 & 2,236 & 2,069 & 7,942 \\
\hline 2 & 2,634 & 807 & 5,664 & 6,161 & 5,010 & 3,050 & 14,616 & 2,864 & 2,625 & 8,569 \\
\hline 2.5 & 3,164 & 1,643 & 5,954 & 6,740 & 6,377 & 6,304 & 16,510 & 3,531 & 3,148 & 9,158 \\
\hline 3 & 3,694 & 3,395 & 6,214 & 7,338 & 7,754 & 10,360 & 18,325 & 4,158 & 3,748 & 9,757 \\
\hline 3.5 & 4,477 & 6,247 & 6,294 & 7,896 & 9,012 & 14,316 & 20,229 & 5,644 & 4,350 & 10,365 \\
\hline 4 & 5,260 & 7,854 & & 8,455 & 10,180 & 17,213 & 20,698 & 6,422 & 4,905 & 10,973 \\
\hline 4.5 & 5,905 & 9,062 & & 9,003 & 11,168 & 20,819 & & 6,979 & 5,475 & 11,600 \\
\hline 5 & 6,550 & 10,210 & & 9,551 & 12,106 & 25,884 & & 7,516 & 6,004 & 11,961 \\
\hline 5.5 & 7,235 & 11,228 & & 10,120 & 12,964 & 30,440 & & 8,102 & 6,553 & \\
\hline 6 & 7,920 & 12,156 & & 10,937 & 13,663 & 34,136 & & 8,803 & 7,173 & \\
\hline 6.5 & 8,720 & 12,924 & & & 14,381 & 38,571 & & 9,648 & 7,722 & \\
\hline 7 & 9,520 & 13,573 & & & 15,439 & 42,008 & & 10,444 & 8,232 & \\
\hline 7.5 & 10,190 & 14,182 & & & & 45,814 & & 11,184 & 8,751 & \\
\hline 8 & 10,860 & 14,780 & & & & 48,352 & & 11,961 & 9,221 & \\
\hline 8.5 & 11,620 & 15,379 & & & & 50,649 & & & & \\
\hline 9 & 12,380 & 16,008 & & & & 53,047 & & & & \\
\hline 9.5 & 13,190 & 16,637 & & & & 56,543 & 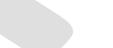 & & & \\
\hline 10 & 14,000 & 17,305 & & & & 58,442 & & & & \\
\hline 10.5 & 14,705 & 18,074 & & & & 60,240 & & & & \\
\hline 11 & 15,410 & 18,992 & & & & 62,038 & & & & \\
\hline 11.5 & 16,195 & 19,850 & & & . & 63,936 & & & & \\
\hline 12 & 16,980 & 20,659 & & & 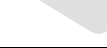 & 65,834 & & & & \\
\hline 12.5 & 17,860 & 21,377 & & & & 66,733 & & & & \\
\hline 13 & 18,740 & 22,046 & & & & & & & & \\
\hline 13.5 & 19,720 & 22,485 & & & & & & & & \\
\hline 14 & 20,700 & & & & & & & & & \\
\hline 14.5 & 21,715 & & & & & & & & & \\
\hline 15 & 22,730 & & & & & & & & & \\
\hline 15.5 & 23,845 & & & & & & & & & \\
\hline 16 & 24,960 & & & & & & & & & \\
\hline 16.5 & 26,135 & & & & & & & & & \\
\hline 17 & 27,310 & & & & & & & & & \\
\hline 17.5 & 28,510 & & & & & & & & & \\
\hline 18 & 29,710 & & & & & & & & & \\
\hline 18.5 & 31,070 & & & & & & & & & \\
\hline
\end{tabular}


Table 4. Volume according to the change in reservoir height, Measurement

\begin{tabular}{|c|c|c|c|c|c|c|c|c|c|c|}
\hline \multirow{2}{*}{$\mathbf{h}(\mathbf{m})$} & $\mathbf{R}(\mathbf{1})$ & $\mathbf{R}(2)$ & $\mathbf{R}(\mathbf{3})$ & $\mathbf{R}(4)$ & $\mathbf{R}(\mathbf{5})$ & $\mathbf{R}(\mathbf{6})$ & $\mathbf{R}(7)$ & $\mathbf{R}(\mathbf{8})$ & $\mathbf{R}(\mathbf{9})$ & $\mathbf{R}(10)$ \\
\hline & \multicolumn{10}{|c|}{$V\left(m^{3}\right)$} \\
\hline 0 & 0 & 0 & 0 & 0 & 0 & 0 & 0 & 0 & 0 & 0 \\
\hline 0.5 & 843 & 14 & 1,109 & 342 & 9 & 1 & 3 & 333 & 14 & 1,397 \\
\hline 1 & 2,081 & 139 & 4,742 & 2,719 & 891 & 51 & 1,497 & 1,555 & 790 & 6,468 \\
\hline 1.5 & 3,866 & 485 & 8,021 & 7,072 & 3,698 & 696 & 10,084 & 3,268 & 2,724 & 12,631 \\
\hline 2 & 6,209 & 1,223 & 11,296 & 11,456 & 7,337 & 3,393 & 24,337 & 5,633 & 4,793 & 18,684 \\
\hline 2.5 & 9,074 & 3,032 & 14,828 & 15,916 & 12,380 & 10,065 & 37,152 & 8,729 & 7,339 & 24,725 \\
\hline 3 & 12,447 & 7,496 & 18,575 & 20,898 & 18,904 & 22,101 & 50,314 & 12,497 & 10,493 & 31,358 \\
\hline 3.5 & 16,873 & 16,764 & 19,969 & 26,434 & 26,628 & 38,903 & 65,352 & 18,484 & 14,348 & 38,654 \\
\hline 4 & 22,541 & 28,048 & & 32,472 & 35,287 & 57,597 & 71,632 & 25,894 & 18,713 & 46,605 \\
\hline 4.5 & 28,638 & 37,883 & & 39,047 & 44,598 & 78,995 & & 32,248 & 23,585 & 55,242 \\
\hline 5 & 35,061 & 47,985 & & 46,153 & 54,452 & 108,694 & & 38,656 & 28,955 & 61,628 \\
\hline 5.5 & 42,251 & 58,748 & & 53,863 & 64,935 & 145,179 & & 45,719 & 34,819 & \\
\hline 6 & 50,239 & 69,939 & & 64,733 & 75,638 & 182,608 & & 53,887 & 41,495 & \\
\hline 6.5 & 59,322 & 81,296 & & & 86,689 & 223,799 & & 63,618 & 48,756 & \\
\hline 7 & 69,586 & 92,527 & & & 102,040 & 268,195 & & 74,511 & 56,214 & \\
\hline 7.5 & 80,121 & 103,870 & & & & 314,278 & & 85,839 & 64,090 & \\
\hline 8 & 90,831 & 115,645 & & & & 360,545 & & 98,851 & 72,050 & \\
\hline 8.5 & 102,621 & 127,982 & & & & 403,833 & & & & \\
\hline 9 & 115,560 & 141,053 & & & & 448,935 & & & & \\
\hline 9.5 & 129,512 & 154,882 & & & & 501,878 & & & & \\
\hline 10 & 144,515 & 169,540 & & & & 555,358 & r & & & \\
\hline 10.5 & 159,743 & 185,581 & & & & 602,910 & & & & \\
\hline 11 & 175,119 & 203,713 & & & & 651,780 & & & & \\
\hline 11.5 & 191,684 & 223,206 & & & & 703,008 & & & & \\
\hline 12 & 209,500 & 242,931 & & & & 756,668 & & & & \\
\hline 12.5 & 228,725 & 262,618 & & & te & 791,556 & & & & \\
\hline 13 & 249,429 & 282,162 & & & & & & & & \\
\hline 13.5 & 271,720 & 297,392 & & & & & & & & \\
\hline 14 & 295,672 & & & & & & & & & \\
\hline 14.5 & 320,869 & & & & & & & & & \\
\hline 15 & 347,338 & & & & & & & & & \\
\hline 15.5 & 375,627 & & & & & & & & & \\
\hline 16 & 405,814 & & 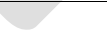 & & & & & & & \\
\hline 16.5 & 437,629 & & & & & & & & & \\
\hline 17 & 471,118 & & & & & & & & & \\
\hline 17.5 & 506,008 & & & & & & & & & \\
\hline 18 & 542,319 & & & & & & & & & \\
\hline 18.5 & 584,400 & & & & & & & & & \\
\hline
\end{tabular}


Table 5. Volume according to the change in reservoir height, Estimation

\begin{tabular}{|c|c|c|c|c|c|c|c|c|c|c|}
\hline \multirow{2}{*}{$\mathbf{h}(\mathbf{m})$} & $\mathbf{R}(\mathbf{1})$ & $\mathbf{R}(2)$ & $\mathbf{R}(\mathbf{3})$ & $\mathbf{R}(4)$ & $\mathbf{R}(5)$ & $\mathbf{R}(6)$ & $\mathbf{R}(7)$ & $\mathbf{R}(\mathbf{8})$ & $\mathbf{R}(\mathbf{9})$ & $\mathbf{R}(10)$ \\
\hline & \multicolumn{10}{|c|}{$\mathrm{V}\left(m^{3}\right)$} \\
\hline 0 & 0 & 0 & 0 & 0 & 0 & 0 & 0 & 0 & 0 & 0 \\
\hline 0.5 & 252 & 15 & 1,007 & 371 & 27 & 2 & 4 & 258 & 13 & 1,021 \\
\hline 1 & 1,273 & 143 & 4,512 & 2,824 & 1,328 & 79 & 1,696 & 1,333 & 759 & 5,343 \\
\hline 1.5 & 2,714 & 494 & 7,755 & 7,243 & 4,731 & 907 & 10,928 & 2,904 & 2,651 & 10,908 \\
\hline 2 & 4,708 & 1,240 & 11,009 & 11,655 & 8,769 & 4,109 & 25,812 & 5,101 & 4,694 & 16,511 \\
\hline 2.5 & 7,226 & 3,063 & 14,523 & 16,126 & 14,234 & 11,692 & 38,908 & 7,996 & 7,217 & 22,159 \\
\hline 3 & 10,256 & 7,557 & 18,252 & 21,116 & 21,198 & 24,995 & 52,253 & 11,536 & 10,344 & 28,372 \\
\hline 3.5 & 14,256 & 16,875 & 21,888 & 26,660 & 29,341 & 43,182 & 67,469 & 17,156 & 14,171 & 35,212 \\
\hline 4 & 19,416 & 28,203 & & 32,702 & 38,383 & 63,057 & 81,854 & 24,134 & 18,509 & 42,674 \\
\hline 4.5 & 25,046 & 38,061 & & 39,279 & 48,031 & 85,572 & & 30,154 & 23,354 & 50,787 \\
\hline 5 & 31,044 & 48,178 & & 46,385 & 58,183 & 116,758 & & 36,240 & 28,696 & 58,900 \\
\hline 5.5 & 37,795 & 58,952 & & 54,095 & 68,942 & 154,890 & & 42,953 & 34,533 & \\
\hline 6 & 45,329 & 70,149 & & 63,170 & 79,880 & 193,726 & & 50,717 & 41,179 & \\
\hline 6.5 & 53,918 & 81,509 & & & 91,142 & 236,298 & & 59,966 & 48,409 & \\
\hline 7 & 63,648 & 92,739 & & & 104,371 & 282,028 & & 70,325 & 55,839 & \\
\hline 7.5 & 73,691 & 104,079 & & & & 329,333 & & 81,108 & 63,686 & \\
\hline 8 & 83,947 & 115,848 & & & & 376,663 & & 92,582 & 71,888 & \\
\hline 8.5 & 95,253 & 128,178 & & & & 420,754 & & & & \\
\hline 9 & 107,676 & 141,242 & & & & 466,633 & & & & \\
\hline 9.5 & 121,093 & 155,062 & & & & 520,554 & & & & \\
\hline 10 & 135,542 & 169,710 & & & & 574,925 & & & & \\
\hline 10.5 & 150,249 & 185,740 & & & & 623,076 & & & & \\
\hline 11 & 165,136 & 203,861 & & & & 672,527 & & & & \\
\hline 11.5 & 181,184 & 223,342 & & & & 724,350 & & & & \\
\hline 12 & 198,453 & 243,053 & & & & 778,621 & & & & \\
\hline 12.5 & 217,097 & 262,724 & & & & 828,546 & & & & \\
\hline 13 & 237,186 & 282,249 & & & & & & & & \\
\hline 13.5 & 258,826 & 300,583 & & & & & & & & \\
\hline 14 & 282,091 & & & & & & & & & \\
\hline 14.5 & 306,586 & & & & & & & & & \\
\hline 15 & 332,337 & & & & & & & & & \\
\hline 15.5 & 359,873 & & & & & & & & & \\
\hline 16 & 389,269 & & & & & & & & & \\
\hline 16.5 & 420,269 & & & & & & & & & \\
\hline 17 & 452,920 & & & & & & & & & \\
\hline 17.5 & 486,960 & & & & & & & & & \\
\hline 18 & 522,408 & & & & & & & & & \\
\hline 18.5 & 560,528 & & & & & & & & & \\
\hline
\end{tabular}


Table 6. Reservoir volume comparison and results

\begin{tabular}{|c|c|c|c|}
\hline Classification & Measurement $\left(\boldsymbol{m}^{\mathbf{3}}\right)$ & Estimation $\left(\boldsymbol{m}^{\mathbf{3}}\right)$ & Error rate $(\boldsymbol{\%})$ \\
\hline \hline R1 & 584,400 & 560,528 & 4.26 \\
\hline R2 & 297,392 & 300,583 & 1.07 \\
\hline R3 & 19,969 & 21,888 & 9.61 \\
\hline R4 & 64,733 & 63,170 & 2.47 \\
\hline R5 & 102,040 & 104,371 & 4.28 \\
\hline R6 & 791,556 & 828,546 & 14.27 \\
\hline R7 & 71,632 & 81,854 & 6.77 \\
\hline R8 & 98,851 & 92,582 & 0.23 \\
\hline R9 & 72,050 & 71,888 & 4.63 \\
\hline R10 & 61,628 & 58,900 & \\
\hline
\end{tabular}

314

316

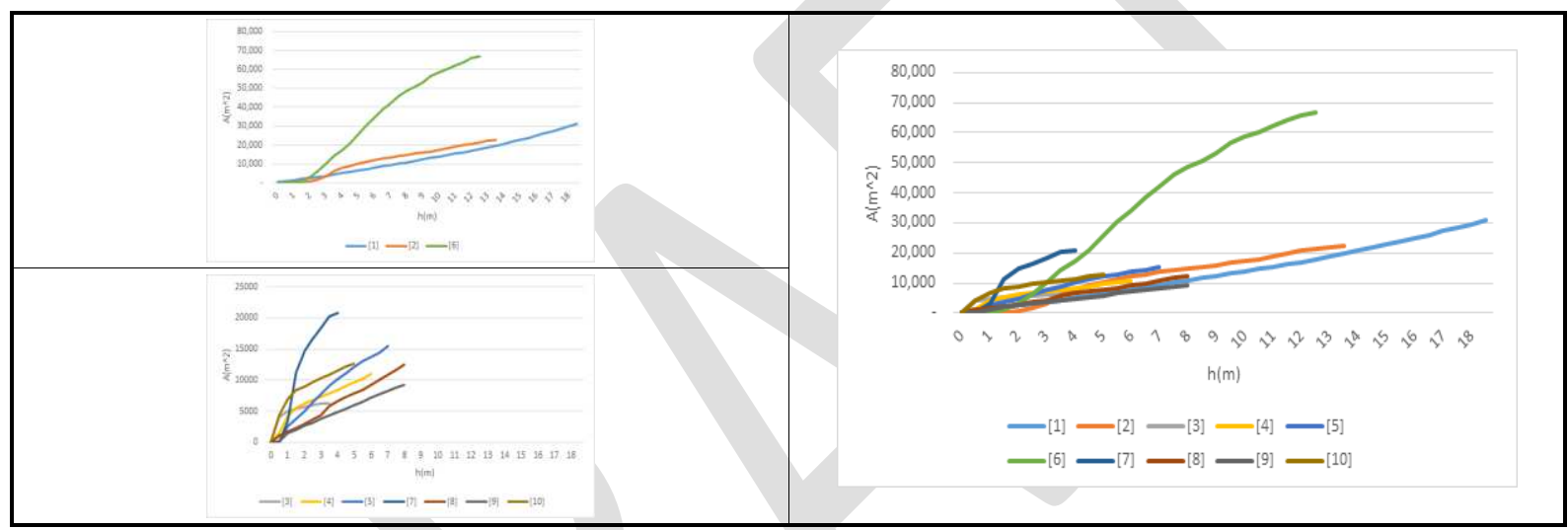

Figure. 7 A-h relationship curve

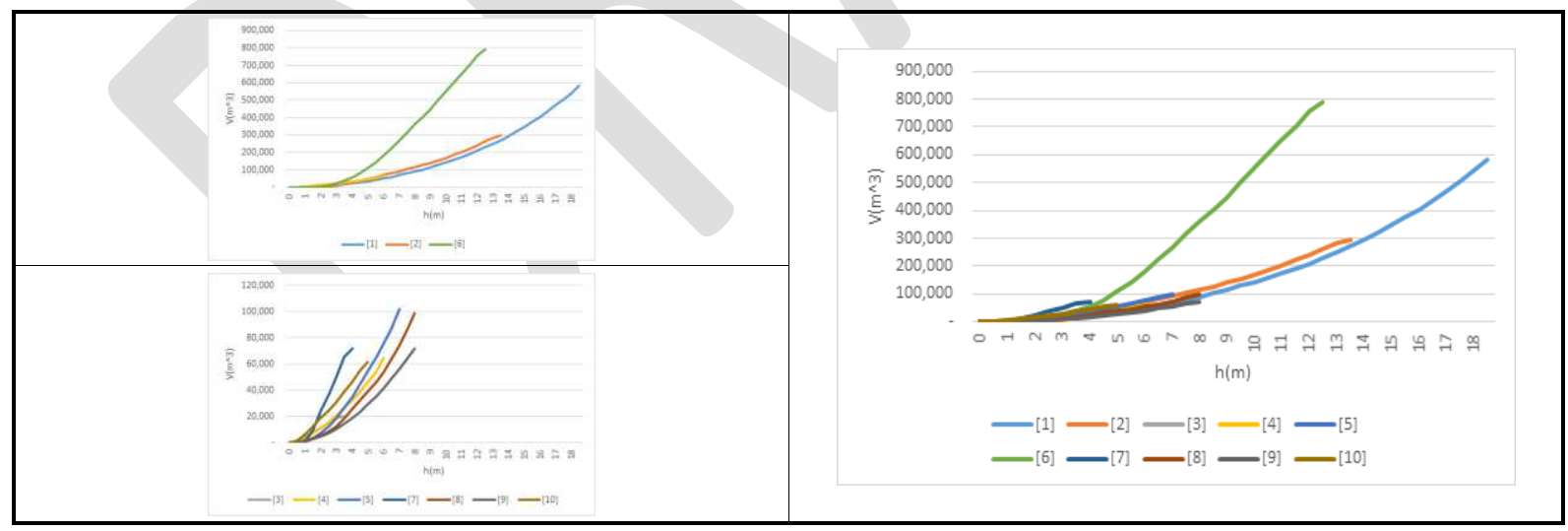

Figure. $8 \mathrm{~V}$-h relationship curve 


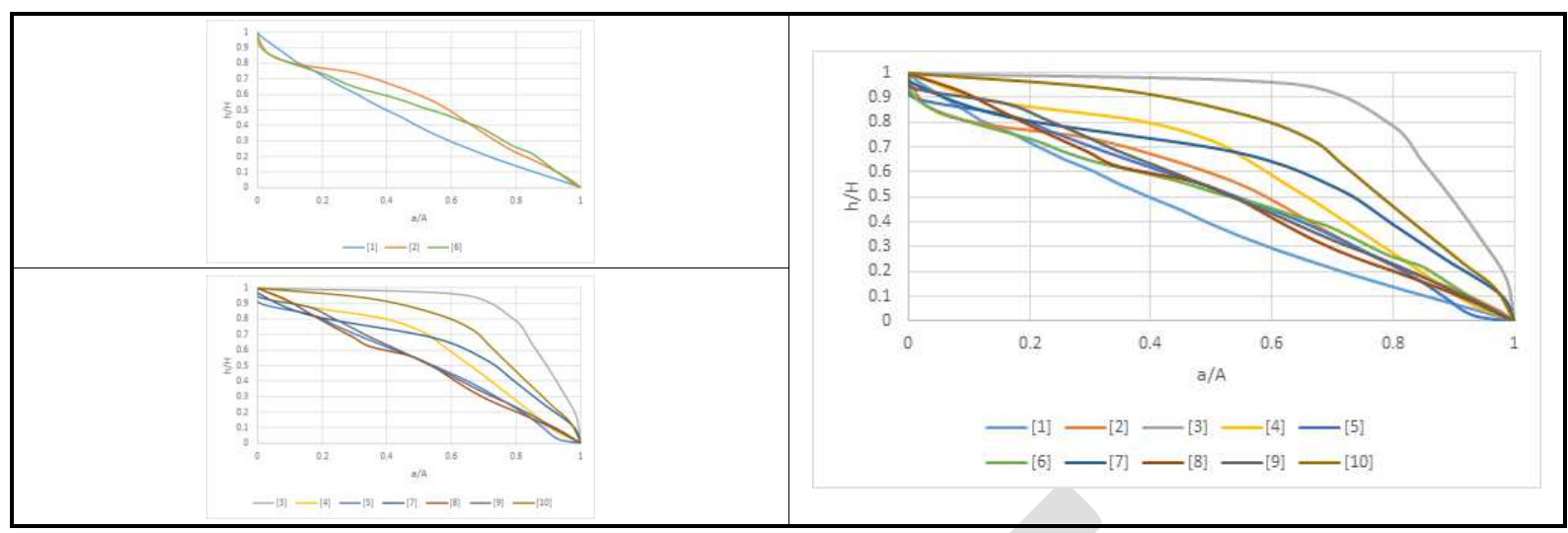

Figure. 9 Hypsometric curves at 10 locations including Ga-Gog Reservoir

Table 7. Analysis of the results of reservoir morphological characteristics

\begin{tabular}{|c|c|c|c|c|c|}
\hline Classification & $\begin{array}{c}\text { Value } \\
\text { (Leonard, 1999) }\end{array}$ & Classification & $\begin{array}{c}\text { Value } \\
\text { (Lehner, 2004) }\end{array}$ & Classification & $\begin{array}{c}\text { Value } \\
\text { (Takeuchi, 1997) }\end{array}$ \\
\hline $\mathrm{R} 1$ & 5.70 & $\mathrm{R} 1$ & 1.45 & $\mathrm{R} 1$ & 3.65 \\
\hline $\mathrm{R} 2$ & 5.38 & $\mathrm{R} 2$ & 1.08 & $\mathrm{R} 2$ & 3.05 \\
\hline $\mathrm{R} 3$ & 3.76 & R3 & 2.09 & $\mathrm{R} 3$ & 1.30 \\
\hline $\mathrm{R} 4$ & 2.00 & $\mathrm{R} 4$ & 17.87 & $\mathrm{R} 4$ & 0.86 \\
\hline R5 & 2.78 & R5 & 4.23 & R5 & 1.36 \\
\hline R6 & 13.18 & R6 & 0.61 & R6 & 11.32 \\
\hline R7 & 1.75 & R7 & 1.85 & R7 & 0.95 \\
\hline $\mathrm{R} 8$ & 2.60 & $\mathrm{R} 8$ & 6.86 & $\mathrm{R} 8$ & 1.17 \\
\hline R9 & 4.29 & R9 & 1.69 & R9 & 1.71 \\
\hline $\mathrm{R} 10$ & 2.19 & $\mathrm{R} 10$ & 2.11 & $\mathrm{R} 10$ & 0.98 \\
\hline
\end{tabular}

\subsection{Analysis of reservoir characteristics through cluster analysis}

To identify the characteristics of the reservoirs with different specifications, cluster analysis was conducted using the basic specifications of each reservoir. As shown in Table 8, the specifications of the ten reservoirs, including the Ga-Gog Reservoir, were used as input data. The input data included the basin area, useful capacity, area of full water, levee height, levee length, permissible area, area irrigated, and frequency of drought. 
Table 8. Basic specifications of 10 places including Ga-Gog Reservoir

\begin{tabular}{|c|c|c|c|c|c|c|c|c|}
\hline Classification & $\begin{array}{l}\text { Basin } \\
\text { area } \\
\left(m^{2}\right)\end{array}$ & $\begin{array}{c}\text { Useful } \\
\text { capacity } \\
\left.\left(1,000 m^{3}\right)\right)\end{array}$ & $\begin{array}{c}\text { Area of } \\
\text { full water } \\
\quad\left(\mathrm{m}^{2}\right)\end{array}$ & $\begin{array}{c}\text { Levee } \\
\text { height } \\
\text { (m) }\end{array}$ & $\begin{array}{c}\text { Levee } \\
\text { length } \\
\text { (m) }\end{array}$ & $\begin{array}{c}\text { Permissible } \\
\text { area } \\
\text { (ha) }\end{array}$ & $\begin{array}{c}\text { Area } \\
\text { irrigated } \\
\text { (ha) }\end{array}$ & $\begin{array}{l}\text { Frequency } \\
\text { of drought } \\
\quad \text { (year) }\end{array}$ \\
\hline $\mathrm{R}(1)$ & $1,500,000$ & 480 & 31,070 & 12.5 & 84 & 35 & 28 & 1 \\
\hline $\mathrm{R}(2)$ & 530,000 & 280 & 22,530 & 6.2 & 172 & 8.7 & 8.7 & 10 \\
\hline $\mathrm{R}(3)$ & 600,000 & 28.9 & 6,300 & 8.5 & 101 & 10 & 6 & 1 \\
\hline $\mathrm{R}(4)$ & $1,100,000$ & 35.4 & 10,970 & 18 & 170 & 36.6 & 25 & 1 \\
\hline $\mathrm{R}(5)$ & $1,750,000$ & 82.1 & 15,470 & 12.5 & 130 & 47 & 12 & 10 \\
\hline $\mathrm{R}(6)$ & $2,250,000$ & 349 & 66,800 & 10 & 207 & 67.9 & 40.6 & 10 \\
\hline $\mathrm{R}(7)$ & $1,020,000$ & 80 & 20,760 & 6.3 & 180 & 28.1 & 23.1 & 1 \\
\hline $\mathrm{R}(8)$ & 400,000 & 55.4 & 12,460 & 14.1 & 140 & 14 & 9 & 10 \\
\hline $\mathrm{R}(9)$ & 410,000 & 58.2 & 9,230 & 10.2 & 112 & 10.4 & 8 & 10 \\
\hline $\mathrm{R}(10)$ & 580,000 & 47.3 & 12,590 & 7.6 & 241 & 42.2 & 15 & 1 \\
\hline
\end{tabular}

As shown in Figure. 10, the cluster analysis classified the reservoirs into two groups: group (I) with reservoirs whose useful capacity and area of full water were large, including R1, R2, and R6, and group (II) with reservoirs whose useful capacity and area of full water were small, including R3, R4, R5, R7, R8, R9, and R10. The results of conducting cluster analysis using the basic specifications of the reservoirs showed that the reservoirs could be classified based on the useful capacity and area of full water, which were identified as indicators that were more influential than other basic specifications in the cluster analysis process.

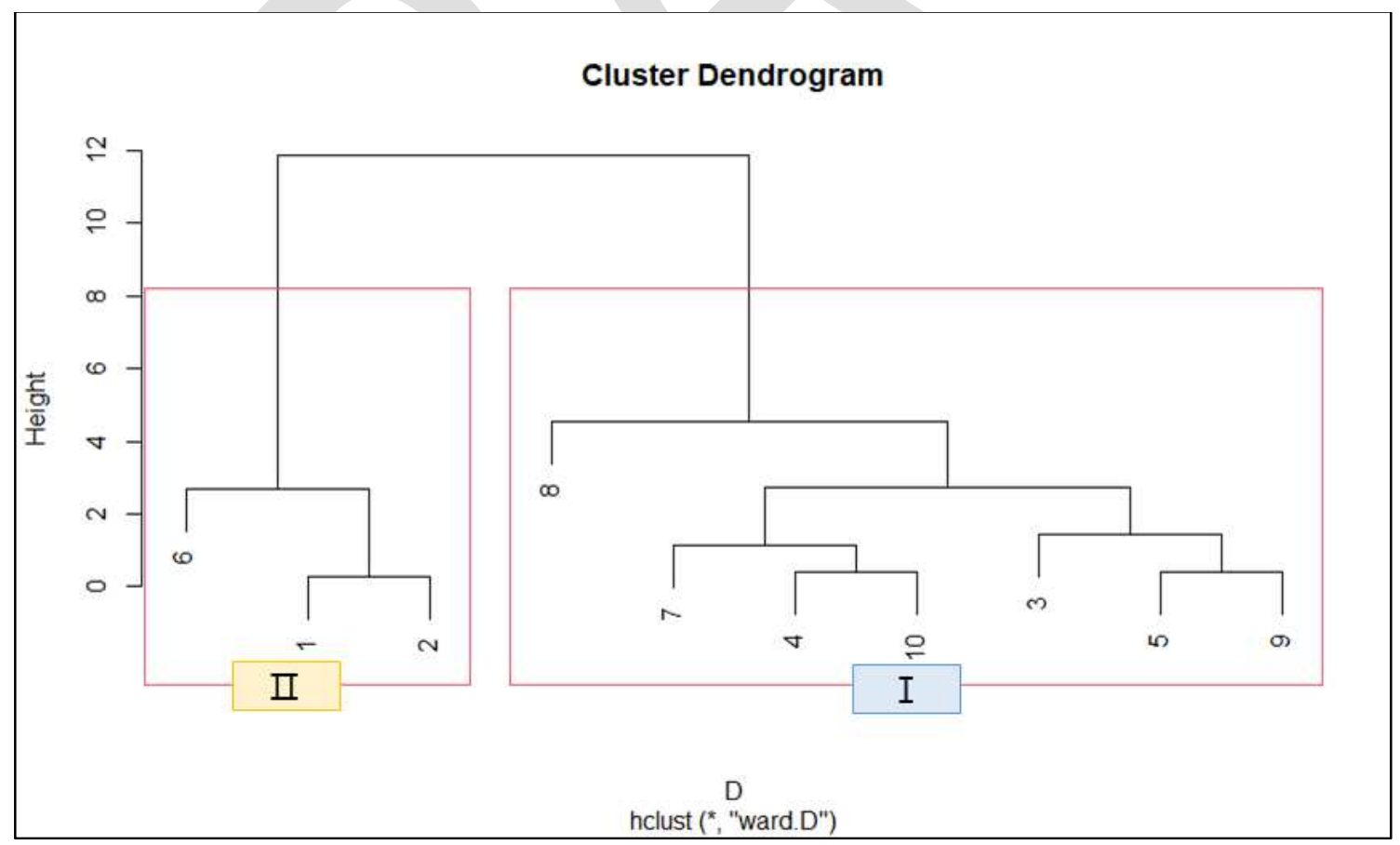




\subsection{Morphological analysis of the collapsed reservoirs using cluster analysis and HC}

HC and the cluster analysis method were applied to reservoirs that had collapsed and caused damage in the past. The reservoirs were located near Miryang city, Gyeongsangnam province, and only the recent damage cases were applied. The Sandae Reservoir located in Gyeongju city, Gyeongsangbuk province, which collapsed in 2013, has an area of full water of $49,200 \mathrm{~m}^{2}$, a useful capacity of 194.4 thousand $\mathrm{m}^{3}$, a levee height of $12.2 \mathrm{~m}$, and a levee length of $210 \mathrm{~m}$. The Goeyeon Reservoir located in Yeongcheon city, Gyeongsangbuk province, which collapsed in 2014, has an area of full water of $61,000 \mathrm{~m}^{2}$, a useful capacity of 61.42 thousand $\mathrm{m}^{3}$, a levee height of $5.5 \mathrm{~m}$, and a levee length of $160 \mathrm{~m}$. In this study, HC and cluster analysis were applied to the Sandae and Goeyeon Reservoirs, which are located near the ten target reservoirs and caused damage in the past.

The morphology index was found to be 11.65 for the Sandae Reservoir and 26.68 for the Goeyeon Reservoir. These high morphology index values indicate that the reservoirs are deeper compared to other reservoirs. The results of the storage-area of full water-levee height relationship were found to be 1.13 for the Sandae Reservoir and 2.26 for the Goeyeon Reservoir, indicating that they had a larger area of full water than other reservoirs. The results of the storage-area of full water relationship were 6.15 for the Sandae Reservoir and 8.87 for the Goeyeon Reservoir, indicating that they had larger storage than other reservoirs.

Cluster analysis was conducted using the specifications of the ten target reservoirs as well as the Sandae (11) and Goeyeon (12) Reservoirs as input data. The cluster analysis classified the reservoirs into three groups: group (I) with the R3, R4, R5, R7, R8, R9, and R10 reservoirs whose area of full water and useful capacity were relatively small; group (II) with the R1, R2, and R6 reservoirs whose area of full water and useful capacity were relatively large; and group (III) with the Sandae (11) and Goeyeon Reservoirs whose area of full water and useful capacity were largest (Figure. 11).

To identify the characteristics of each group, the morphological characteristics of the reservoirs were investigated using their HCs. It was found that group (I) had the original ground surface not significantly eroded and group (II) had the original ground surface significantly eroded. Group (III) had the original ground surface further eroded (Figure. 11).

The Sandae and Goeyeon Reservoirs that collapsed had the larger storage and area than the other reservoirs, and the HC results showed that considerable erosion occurred in their watersheds. In other words, the Sandae and Goeyeon Reservoirs had insufficient allowable storage capacity compared to other reservoirs.

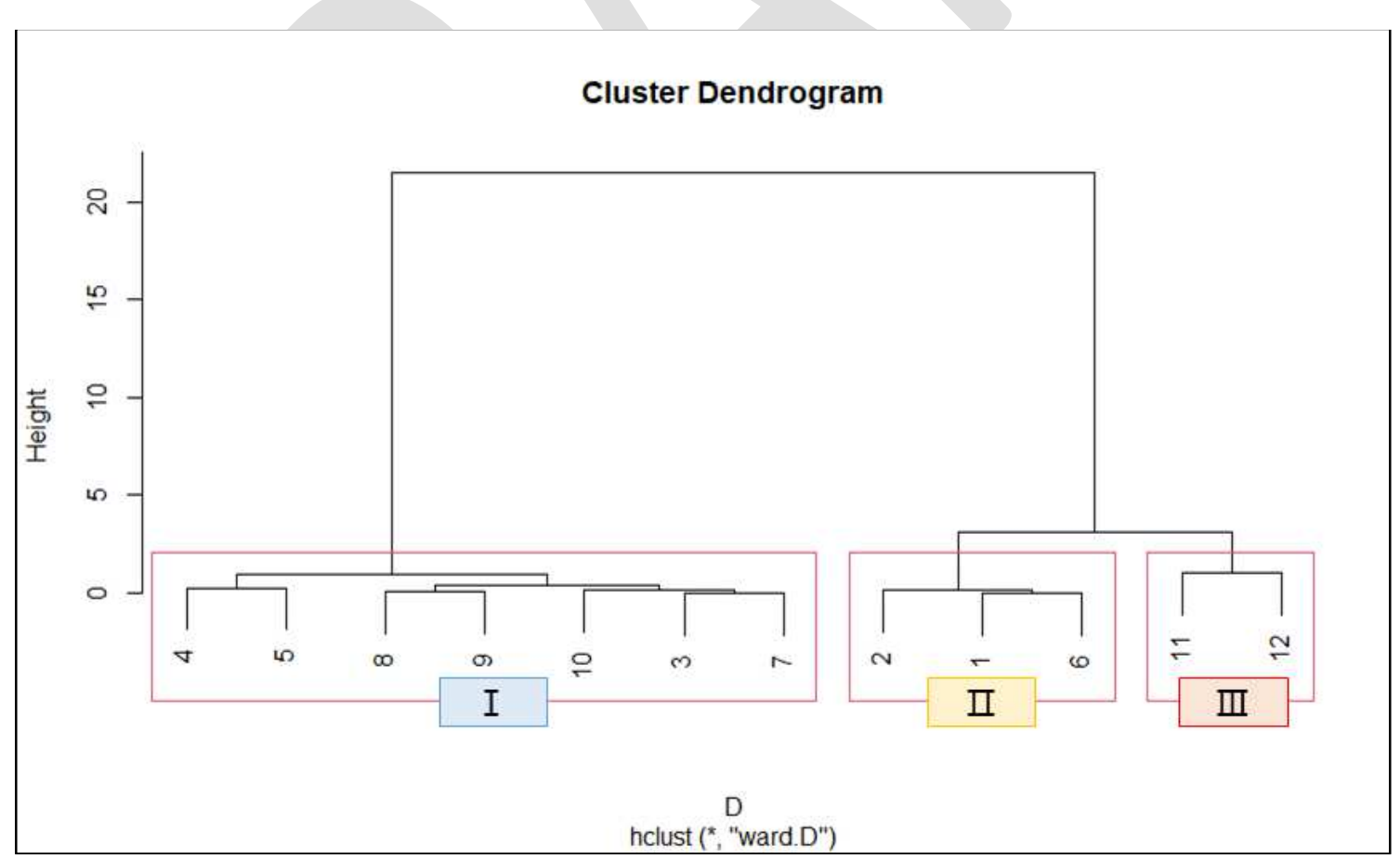

Figure. 11 Cluster analysis result using collapsed reservoir 

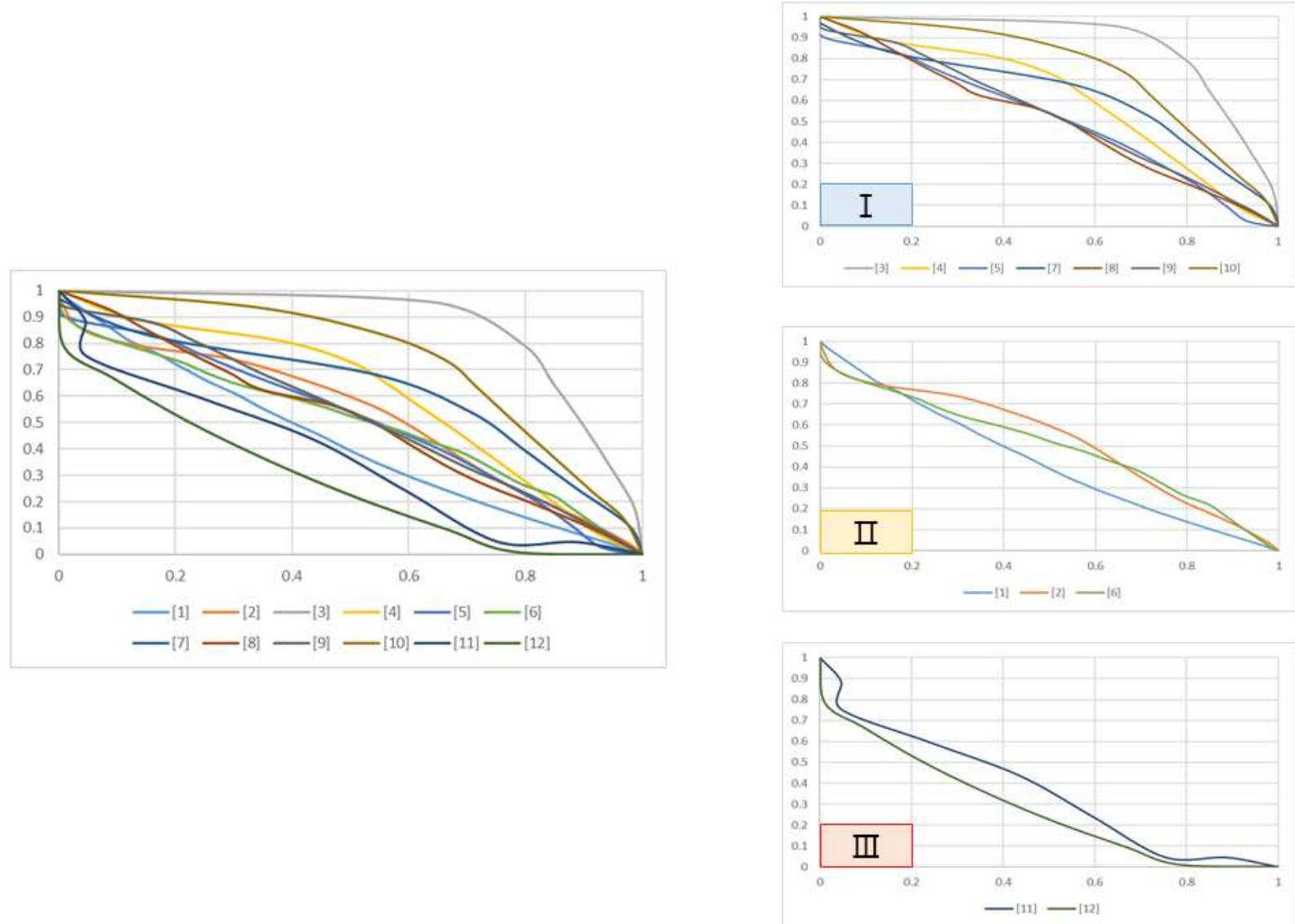

\section{Conclusion}

Figure. 12 Altitude distribution curve result using collapsed reservoir

In this study, the geometry of unmeasured reservoirs was constructed using their topographic information, and morphological analysis was conducted for them. The hypsometric curve (HC) was created for each reservoir to understand their geometry and identify the area by elevation and storage capacity. In addition, the morphology index was quantitatively presented through the analysis of the storage-area of full water relationship for each reservoir. The topographic and morphological analysis of reservoirs that had collapsed due to aging, insufficient management, and flooding were analyzed to identify the potential causes of collapse.

(1) The area by elevation and volume were calculated for ten reservoirs located in Miryang city, Gyeongsangnam province, including the Ga-Gog Reservoir, using digital topographic maps. When the results were compared with the volumes of the reservoirs measured by the National Disaster Management Research Institute, the error rate ranged from 0.23 to $14.27 \%$. The error rate was excellent as its average value was approximately $5.03 \%$. In addition, $\mathrm{HC}$ was created for each reservoir using the area by elevation and volume.

(2) Cluster analysis was conducted to classify similar types of reservoirs into groups using basic specifications, such as the basin area, useful capacity, and area of full water. The cluster analysis classified the reservoirs into two groups: the R1, R2, and R6 reservoirs whose useful capacity and area of full water were large and the R3, R4, R5, R7, R8, R9, and R10 reservoirs whose useful capacity and area of full water were small. The useful capacity and area of full water were identified as indicators that had a larger impact on the cluster analysis results than the other specifications.

(3) When the results of the morphology index, storage-area of full water-levee height relationship, and storage-area of full water 
relationship were comprehensively examined, it was found that the R3, R4, R5, R7, R8, R9, and R10 reservoirs had a relatively lower depth and a relatively smaller area of full water compared to the R1, R2, and R6 reservoirs.

(4) $\mathrm{HC}$ and the cluster analysis method were applied to reservoirs that had collapsed and caused damage in the past. The cluster analysis classified these reservoirs and the ten target reservoirs into three groups: group (I), group (II), and group (III). The HCs of the collapsed reservoirs exhibited the convex downward shape compared to other normal reservoirs, indicating that they were significantly aged. In other words, the collapsed reservoirs were subjected to considerable erosion.

Each reservoir has different basic specifications, such as the area of full water and storage capacity. If the geometry of reservoirs is understood and the common characteristics of similar types of reservoirs are classified and identified using morphological analysis and HC, they are expected to be used as measures to reduce the damage caused by the collapse of reservoirs. It will be possible to reduce damage through proactive disaster management if the potential causes of reservoir collapse can be identified before the occurrence of the disaster.

\section{Acknowledgement}

This work was supported by the Extreme Disaster Response Technology Development Program (2018-MOIS31-009) funded by the Ministry of the Interior and Safety.

\section{Reference}

Chang, Y. K., Park, J. Y., Moon, D. Y. and Kang, I. J. 2003. Calculation of Reservoir Capacity by Combination of GPS and Echo Sounder, Proceedings of the Korean Society of Surveying, Geodesy, Photogrammetry and Cartography, pp.467-470

Choi, B. G. and Lee, H. S. 2007. Measuring Water Volume of Reservoir by Echosounding”, Journal of The Korea Society For GeospatIal Information System, Vol.15, No.1, pp. 55-59

Dargahi, B., \& Setegn, S. G. (2011). Combined 3D hydrodynamic and watershed modelling of Lake Tana, Ethiopia. Journal of Hydrology, 398(1-2), 44-64.

Fassoni-Andrade, A. C., de Paiva, R. C. D., \& Fleischmann, A. S. (2020). Lake topography and active storage from satellite observations of flood frequency. Water Resources Research, 56(7), e2019WR026362.

Graf, W.L., 1999. Dam nation: a geographic census of American dams and their large-scale hydrologic impacts. Water Resources Research 35(4): 1305-1311.

Han, J. W., Ryu, J. H. and Cho, J. H, 2009. Hydro-hypsographic Analysis for Understanding of Flushing Characteristics in Garolim Bay Journal of Wetlands Research, Vol. 11, No. 2, pp. 39-46.

Han, S.M., G.S. Hwang, S.Y. Choe, and J.W. Park, 2014. A study on classifying algorithm of disaster recovery resources using statistical method. Journal of Korean Society of Hazard Mitigation. Vol. 14, No. 1, pp. 49-58.

Hayashi. M and Kamp, G.V. 2000. Simple equations to represent the volume-area depth relations of shallow wetlands in small topographic depression. Journal of Hydrology, 237, pp. 74-85

Kim, D. H., Kim, J. S., Choi, C. H., Wang, W. J., You, Y. H., and Kim, H. S. (2019) Estimations of Hazard-Triggering Rainfall and Breach Discharge of Aging Reservoir. J. Korean Soc. Hazard Mitig., Vol. 19, No. 7, pp. 421-432.

Kim, J. K., Kim, H. S. and Jeong, S. M. (2002). Estimation of volume-Area-Depth Relationship for Shallow Wetland. Journal of Wetlands Research, Vol. 35, No. 2, pp. 231-240.

Kim., D. H., Kim, J. S., Wang, W. J., Lee, J. S., Jung, J. W., and Kim, H. S. (2020) Analysis of Morphological Characteristics of Collapsed Reservoirs in Korea. J. Korean Soc. Hazard Mitig., Vol. 20, No. 5, pp. 207-216.

Kyoung, M.S., S.D. Kim, B.K. Kim, and H.S. Kim, (2007). Construction of hydrological drought severity-area-duration curves using cluster analysis. Journal of the Korean Society of Civil Engineers Vol. 27, No. 3B, pp. 267-276.

Langbein, W.B. et al., (1947). Topographic characteristics of drainage basin, U.S. Geolological Survey, W.S. Paper 968-C, pp. 125-157.

Lehner, B. and Doll, P. (2004) Development and validation of a global database of lakes. reservoir and wetlands. Journal of Hydrology. Vol. 296, 1-22.

Leonard, J. and Crouzet, P. (1999) Lakes and Reservoir in the EEA area. Topoc Report No. 1/1999. European Environment Agency(EEA), Copenhagen, Denmark.

Li, Y., Zhang, Q., Yao, J., Werner, A. D., \& Li, X. (2014). Hydrodynamic and hydrological modeling of the Poyang Lake 
catchment system in China. Journal of Hydrologic Engineering, 19(3), 607-616.

Lopes, V. A. R., Fan, F. M., Pontes, P. R. M., Siqueira, V. A., Collischonn, W., \& da Motta Marques, D. (2018). A first integrated modelling of a river-lagoon large-scale hydrological system for forecasting purposes. Journal of Hydrology, $565,177-196$. Survey in the Po River, Journal of Hydraulic Engineering, Vol. 137, No. 12, pp. 1576-1587.

McDonald, C.P., J.A. Rover, E.G. Stets, and R.G. Striegl, (2012). The regional abundance and size distribution of lakes and reservoirs in the United States and implications for estimates of global lake extent. Limnology and Oceanography 57(2): 597-606.

Munar, A. M., Cavalcanti, J. R., Bravo, J. M., Fan, F. M., da Motta-Marques, D., \& Fragoso, C. R. (2018). Coupling largescale hydrological and hydrodynamic modeling: Toward a better comprehension of watershed-shallow lake processes. Journal of Hydrology, 564, 424- 441.

Nam, W. H., Kim, T. G., Hong, E. M., Michael J. Hayes., Mark D. Svoboda, (2015). Water Supply Risk Assessment of Agricultural Reservoirs using Irrigation Vulnerability Model and Cluster Analysis. Journal of the Korean Society of Agricultural Engineers. Vol. 57, No. 1, pp. 59-67.

National Disaster Management Research Institute, 2019

Oertel, G.F., Hypsographic, (2001). hydro-hysographic and hydrological analysis of coastal bay environments, Great Machipongo Bay, Virginia. Journal of Coastal Research, Vol. 17, pp. 775-783.

Park, S. K. and Jeong, J. H. (2005). Calculation of Sediment Volume of the Agriculture Reservoir Using DGPS EchoSounder, The Journal of GIS Association of Korea, Vol. 13, No. 3, pp. 297-307

Sarp, G., S. Duzgun, and V. Toprak. Hypsometric properties of the hydrolic basins located on western part of NAFZ. 34th International Symposium on Remote Sensing of Environment, The GEOSS Era: Towards Operational Environmental Monitoring, Sydney, Australia. 2011.

Song, B. G., Oh, J. Y., Kim, S. S., Lee, T. W. and Park, K. H. (2018). Analysis of 3D Topographic Information on Reservoir Using UAV and Echo Sounder, J. Korean Soc. Hazard Mitig, Vol.18, No.7, pp.563-568.

Takeuchi, K. (1997) Least marginal environmental impact rule for reservoir development. Hydrological Science Journal. Vol. 42, No. 4, pp. 583-597.

Zhang, L., Lu, J., Chen, X., Liang, D., Fu, X., Sauvage, S., \& Sanchez Perez, J.-M. (2017). Stream flow simulation and verification in ungauged zones by coupling hydrological and hydrodynamic models: A case study of the Poyang Lake ungauged zone. Hydrology and Earth System Sciences, 21(11), 5847-5861. 